\title{
Construction of Practical Teaching System for Technical Skilled Talents Based on Professional Ability Training
}

\author{
Jiangbo Chen \\ Qingdao Huanghai University \\ Qingdao, Shandong, China \\ Yuanyuan $\mathrm{Xu}$ \\ Qingdao Huanghai University \\ Qingdao, Shandong, China
}

\author{
Futing Ge \\ Qingdao Huanghai University \\ Qingdao, Shandong, China
}

Yan $\mathrm{Li}^{*}$

Qingdao Economic \& Technological Development Area No.2 Experimental Primary School

Qingdao, Shandong, China

\begin{abstract}
In view of the problems such as the single teaching form, one-size-fits-all practice process, lack of enterprise participation, etc, the construction of practical teaching system of cultivating technical skilled talents in Qingdao Huanghai University must take the market demand as guidance, take the output of high quality talents as evaluation index, build practical teaching platforms, control the practical teaching links, innovate the practical teaching methods, improve the practice teaching management mechanism, and construct "double-qualified" teaching faculty and other efficient measures to cultivate high quality technical skilled talents for enterprises and society.
\end{abstract}

Keywords - higher vocational colleges; technical skilled talents; practical teaching system; innovative ability

\section{INTRODUCTION}

With the rapid development of economy and society, science and technology, and higher vocational education in china, the job market of technical skilled talents has varied so greatly that personnel structure and quality specifications are unable to meet the needs of society and industry. In the new situation, globalization, development, innovation, economy, engineering complexity and human sustainable brought new challenges to Chinese engineering education. higher vocational engineering education of china is increasingly showing inadaptability. From the performance of students, they particularly lack the ability of engineering practice, human spirit, the capacity for sustainable development, crosscultural communication skills and so on.

For the problems in the cultivation of vocational education talents, aiming at cultivating the ability for solving the practical engineering problems, and also the innovation \& entrepreneurship ability, the paper constructs threedimensional and three levels laddered practical teaching system, in which the three dimensions include school enterprises and government three levels include basic ability training, innovation ability training and entrepreneurship cultivation. Through the school-enterprise cooperation, enterprise engineers and enterprise projects are introduced into the practical teaching to cultivate the ability for solving the practical engineering problems; The innovation ability is cultivated mainly through the competitions and innovative training projects and so on; The maker space is used as the primary supporter to guide and help the students to start a business. By introducing the concept of OBE into practical teaching, the study aims to realize the conversions in practical teaching, namely, conversion from teacher-centered to student-entered; from knowledge-oriented to target-oriented and from single quality supervision to multiple evaluation.

\section{DETERMINE TRAINING OBJECTIVES, CLARIFY TRAINING} IDEAS, CONSTRUCT PROJECT-DRIVEN CURRICULUM SYSTEM

The purpose of vocational education is to train people and offer services in the process of human growth for the students as well as community. Our responsibilities are as follows: to provide suitable education for the growth and development of students according to the actual situation of the school and the characteristics of students, so that each student could be able to do their best in learning and working.

The objectives of practice teaching highlight creative intelligent skills in the knowledge and skill structure of an application-oriented competent person; the design of instruction emphasizes creativity and versatility; the contents of teaching adapt to the demands of social and economic development, reflecting the application and rapid progress of modern technology.

Based on the CDIO engineering education model and combined with the practical teaching of mechanical innovation design and practice course, integrating innovation education and professional education, building practice teaching system combining inside and outside classes were explored. The practice teaching system of combining theory teaching with innovation practices, combining in-class experiments with outclass practices is made. Theory teaching mainly includes the principle and technique of innovation, scheme innovative 
design, organization and structure innovative design, innovation design simulation and innovation instance, which focuses on the training of thinking ability, design ability and learning ability. Innovation practice module is comprised of in-class experiments and outclass practices, which focuses on the training of practical ability and engineering ability.

With the guidance of such ideas, combined with certain characteristics of current vocational education, we integrated relevant teaching resources after a detailed study on the teaching of mechanical and electrical profession. We also carried out a series of specific research work after studying the actual situation of students and social needs, for instance, an overall planning of the course content, and teaching methods reform. Firstly, integration of current teaching content helps to raise teaching efficiency, by using school-based teaching materials on the basis of national and local materials, which could offer a precise and constructional learning content. Currently, textbooks differ among higher vocational schools. With no common requirements on teaching materials, some higher education teaching content is even directly brought into vocational teaching materials, of which the depth, the applicability can not meet the needs of higher vocational school students. Therefore, a reasonable combination as well as a further improvement of the relevant materials is required. Secondly, strengthen schoo-enterprise joint work to improve practical teaching. By permeating expertise with enterprise culture, the students will better adapt to the enterprise in advance with what they have fully mastered. Thirdly, strengthen professional skill training, perfect certain profession and individualized teaching. Refine professional learning based on its characteristics and the actual needs of students and enterprises, so as to avoid learning so many specialties while obtaining no outstanding specialty. To enable each student to learn at least a fine specialty founded on personal preference so that they will better adapt to future work. Fourthly, learn in doing to stimulate interest and raise teaching efficiency. For some vocational school students, traditional teaching methods have lost their attraction. Practice first could stimulate their interest for further exploration and enthusiasm in positive learning, which will greatly enhance the efficiency of practical teaching. Last but not least, radioactive skill training could effectively enhance teaching efficiency. With the inspiration from traditional master-toapprentice inheritance, we cultivate several capable and outstanding students first, and then enable them to guide other students as their apprentices. It will not only improve teaching efficiency but also solve the problem of teaching staff shortage After such research and experiment, the overall teaching effect is rather obvious and satisfactory, and most students are willing to participate in active learning.

\section{ADJUST THE TEACHING METHOD}

Practical teaching is the main characteristic of higher vocational colleges and universities. It is not only the key symbol for distinguishing between higher education and higher vocational education in general categories, but also the important form for training students to transform their knowledge directly into professional skills and productivity, and to find problems and solve them quickly. More importantly, the process is also an important way for students to hone their will, improve their comprehensive literacy, cultivate their professional ethics and improve their employability. Therefore, every aspect of the process and related factors are particularly important. As the core link and "vitality" of higher vocational colleges and universities, the effect of practical teaching is directly determined by supply and demand, and the quality of talents trained in higher vocational colleges and universities is directly determined by the quality of talents.

Teachers should adopt some innovative and effective methods consciously to design teaching forms. Furthermore, based on the particular vocational education way of thinking, teachers should treat the practical teaching as a situational dynamic developing process and try to use the practical teaching design on situation-Creation consciously, specifically, "problems in real situation" need to be put forwards, through which the learners can interact with the real physical and social environment effectively. By the way of "Legitimate Peripheral", the learners can change from onlookers or participants to the core members in practical community as well as promote their own practical knowledge and ability, what's more, the learners can be exposed the environment of practical cultural edification and realized their personal identity construction. Consequently practical features of Vocational Education are effectively reflected, and the learners change with it.

Application of micro course can solve the problems of production management in the experimental teaching, such as teaching knowledge deviation from the actual demand. Students are difficult in-depth understanding of business practices by traditional experimental class. According to the urgency of applied talents training, we put forward the integration of "production field information+knowledge transfer" micro teaching model, to obtain the production field information through school-enterprise cooperation, and it achieves the teaching objectives of "zero distance contact with enterprise".

Firstly: the integration of teaching material: using VB to design courseware for the fourteen chapters of the course by using PPT, electronic teaching plan, animation library, video library, chart table, problem sets, auto-generating test paper, on-line examination and amusement bar to teach, supervise, study independently and evaluate.

Secondly: the construction and implementation of the "four steps and eight phases" teaching model: classroom teaching is carried out with the "four steps and eight phases". The four steps means "leading, self-study, interaction and consolidation". The eight phases means "situation creation, showing target, self-study guidance, cooperative learning, result check, training consolidation, summary and promotion, and effect evaluation".

Finally: the application of diversified teaching methods, a set of the evaluation schemes and measures: Teaching methods include direct teaching method, multimedia teaching method and network teaching method. The evaluation schemes can evaluate the students' learning performances and abilities 
completely, so it meets the need for higher vocational students' personality development and schools' educational goals.

In view of the lack of engineering quality education and innovation ability training of students in Qingdao Huanghai University, the practice of mechatronical comprehensive experiment teaching based on actual engineering project was discussed in this paper. First, with the help of experts from enterprises, the relationship between professional knowledge, ability and quality was straightened out; course groups, a network curriculum system, and a knowledge support system for comprehensive experiment teaching were established. Next, a comprehensive experiment was developed based on real engineering project which enabled the students to grasp the core technology and the overall concept of a typical mechatronics system. By comprehensive training, the students were urged to apply the basic theory professional knowledge and basic skills which they have learned into an engineering case. Then, the teaching methods were reformed, which brings the core technology of the project into classroom teaching, so that comprehensive experiment can be executed smoothly. Meanwhile, the experiment evaluation method was reformed, which emphasized ability and quality assessment, and stimulated the enthusiasm of the students to do experiments autonomously.

Internship is applied generally in the practice teaching activities of engineering undergraduate education. Such internships provide students with practical work environment, nurture students' ability in professional practice, enhance students' social cognition and professional consciousness, and obtain some work experience as well, which are important for the development of students' capacity and profession.

The integration of graduation practice with dissertation is based on CEEUSRO, and aims at training student' $s$ overall quality and comprehensive ability. The graduation practice and dissertation are integrated into a phase with the combination of research task and job practice by means of cooperation agreement between the university and the training base. A practical teaching pattern of combining graduation practice with dissertation, combining research topic with practical problem-solving, combining education for all around development with skill training has been investigated in order to improve the teaching effectiveness through the cooperation between universities and enterprises.

Fully combined with the open mode of laboratory management, the training for Undergraduate Electronic Design Competition is constantly explored. The improvement of practical ability is investigated from aspects of learning, training and practice, until the competition process. To build up an learning atmosphere in the open laboratory for scientific innovation, the basic training, design works, and optimization design are put into practical teaching process and experimental teaching process. Innovative and practical ideas are penetrated through theoretical, experimental and practical training courses, and finally in the Electronic Design Competition in order to cultivate innovative talents. Practice has proved that, after a longtime training, students could not only get good grades in the competition, but also work smoothly due to the outstanding practical ability.

\section{STRENGTHEN SCHOOL-ENTERPRISE COOPERATION}

The paper proposes a new practice system model with school-enterprise cooperation and major co-construction as the breakthrough point. It is to build industry oriented model and to enhance students' comprehensive application ability and engineering practice ability. The goal-oriented model is depended on manufacturings industry talents' basic ability established by both school and enterprise sides. Based on required professional and vocational skills in the future work as the main line, the maiintegrate teaching resources and to build the corresponding course system with the experiment and practical system to cultivate students' professional knowledge of comprehensive application ability innovation ability and engineering practice ability during the work-integrated learning experiential teaching and engineering practice.

In Qingdao Huanghai University, the research on the construction of practice-bases and practice teaching reform for mechatronics specialty is conducted. In the cooperation platform, job occupation standard of Manufacturing industry should infuse to curriculum system; Using going out and inviting strategy to increase cultivation of practice teaching faculty. Relying on the traditional cooperation partners, integrating the internal resources, our college established the comprehensive practice base for mechatronics specialty. Adopting combination method of learning-research-production to create a win-win cooperation mode between universities and enterprises, it improve enterprises enthusiasm to participate. The cooperation platform supports teachers to learn at enterprises, and allow enterprise members to teach at colleges as part-time teachers. we realize the diversification teaching methods and subject and reform the existing teaching evaluation mechanism. For the training of innovative talents, based on 4 levels of the engineering knowledge, engineering training and practice, engineering comprehension, and research innovation the reform of practice teaching is actively carried out. The reform stimulates students' interest in practice and promotes the education and teaching quality.

\section{STRENGTHEN THE CONSTRUCTION OF TEACHING STAFF}

The experimental teaching team is the main body of the experimental teaching and the executor of the laboratory construction in colleges and universities. The building of experimental teacher team plays an important role in the university experimental development. However, there are many problems on the construction of experimental teaching team because of the lack of attention, the irrational management system and the imperfect assessment indexes. According to the analysis of the present situation of the experimental teaching team, we provides a strategy to construct the experimental teaching team under the two-Level management, and strengthen it from the level of college. Combining with the situation of Qingdao Huanghai University, Mechanical and Electrical Engineering proposes some new methods based on the rule guidance and the target encouragement to expand the training pattern of experimental teachers, motivate the experimental teachers to teach, and promote the sustainable development of the experimental teaching team. It is proved that the training mode for experimental teachers is broadened due to the formulation of 
the targeted special system; and the vitality of experimental teachers can be activated through the establishment of a scientific and effective incentive mechanism.

In recent years, in view of the present actual situation of young teachers in Qingdao Huanghai University, the exploration and practice on the cultivation of young teachers' teaching ability have been carried out, and a certain effect is obtained through building of "three platforms" (i.e., experiment teaching platform, university-enterprise cooperation platform and academic exchange platform), implementating of "three plans" (i.e., young teachers cultivation plan, young teacher training plans and youth key teachers cultivating plans), and developing of "three activities"(i.e., teaching competition and observation activities, teaching research and social practice activities).

\section{IMPROVE THE QUALITY CONTROL SYSTEM}

In the practical teaching quality monitoring system of higher vocational colleges there still exist some problems, just as the monitoring subject still remains to be further expanded, the comprehensiveness of monitoring system remains to be further improved, the systematicness remains to be further optimized and the monitoring method remains to be further researched. The perfect system of practical teaching quality monitoring should be composed of organization management system, content system, method system and security system.

The structure of higher vocational colleges' TQM can use circulation mode, and colleges can take different strategies in planning phase, execution phase, evaluating phase and action processing phase. In the planning phase, they should focus on:1. Perfect vocational colleges' practical teaching.2.Be more publicity to improve the importance of practical teaching.3.Improve the practical teaching and personal cultivating plans.4.Establish the effectiveness of practical teaching management rules between colleges and companies. In the execution phase, to enlarge the scale of vocational colleges' practical teaching monitors, and to diversify the evaluating contents of practical teaching. As well as, to strengthen the guidance and management of students' afterschool practical activities. In the assessment phase, to rationalize the assessment methods of practical teaching, to improve the assessment methods of teaching faculty and to achieve the quality of graduate employment. In the treatment phase, to achieve timely and effectively feedback, through IT to strengthen the support for practical teaching management, and to continually enhance the strategies of monitor.

Qingdao Huanghai University has built up scientific, reasonable and standard practical teaching and quality management system from several aspects and is gaining its perfection, which contributes a lot to increasing practical teaching quality and ensuring that the quality meets the purpose of talents development. The assessments include Level 1 (Employer, students and school) and Level 2 (Practical ability, work attitude, obedience, practice teaching management, insurance of capital and infrastructure, mechanism design and implementation supervision, practice teaching ability of teachers, practice teaching process evaluation of students, achievement assessment of practice teaching) after discuss with enterprises, students, outside practical teaching experts, government officers and other stakeholders. Qingdao Huanghai University established an experienced team for practical teaching supervasion, adopted the scientific method system for practical teaching monitoring system and built the good incentive and restraint mechanism for practical teaching monitoring so as to ensure the steady improvement of practical teaching level

\section{SUMMARY}

Following the law of higher education, strengthening the connotation construction of practice teaching system, cultivating students' cognition, practice, and innovation capability, all kinds of talents who meet the needs of local economy, society and science development are key factors of constructing open practical teaching system. Firstly, discipline system to serve the development of the local economy is oriented by market demand; rounds school's characteristic and emphasizes the application. Secondly, it also needs to constantly strengthen the construction of teachers, gradually increase the comprehensive and design experiments. Lastly, training students' practice ability innovation capability are important for good open practice teaching system.

\section{ACKNOWLEDGMENT}

This work was financially supported by Qingdao education science 13th five-year plan 2018 project+exploration and practice on the training mode of innovative technical talents for electromechanical specialty in deep cooperation between universities and enterprises+QJK135D876, the teaching reform research Projects of Vocational Education in Shandong Province (NO: 2017549), the teaching reform research Projects of Qingdao Huanghai University (NO 2016jiaoxue06).

\section{REFERENCES}

[1] Chen Amei, Qin Junwei, Hu Hanwei, etc. Research and exploration on quality monitoring system of experiment teaching $[\mathrm{J}]$. Experimental Technology and Management, 2011.28(7): 251-252.

[2] Liu Wei, He Xiaorong, Yang Yi. Electrical Professional Engineering Education Reform Based on the Practicing Driven and Enterprise Cooperation[J]. Research and Exploration in Laboratory, 2017.36(10): 248-252.

[3] ZHou Chunyue, Liu Ying, ZHang Hongting,etc. The Research of Laddered Practical Teaching on Outcomes-based Education[J].Research and Exploration in Laboratory, 2016.35(11):206-208.

[4] Liu Tingguo, Huang Jinsong, Guo Jun,etc. The Preliminary Exploration of Improving the Undergraduates' Scientific Research Diathesis in Practice Teaching[J]. Polymer Bulletin, 2015(8):116-122.

[5] Dai Yahong, Li Hong, Wu Yangbo,etc. Reform on practical teaching system for quaternity of "Learning-practice-research-innovation" under background of new engineering[J]. Experimental Technology and Management,2017.34(12): 189-195.

[6] Yang Lingfang, Wu Zhantao. Application of Open Project Based Teaching in Practice Teaching of Materials Forming Specialty[J].Chinese Journal of Chemical Education, 2018.39(2): 55-58. 